\title{
Evaluating the Potential Impact of Reservoir Operation on Fish Communities
}

\author{
Jian-Ping Suen, A.M.ASCE ${ }^{1}$; J. Wayland Eheart, M.ASCE${ }^{2}$; Edwin E. Herricks, Aff.M.ASCE ${ }^{3}$; and \\ Fi-John Chang ${ }^{4}$
}

\begin{abstract}
A developing understanding of instream flow needs now supports maintenance of ecological flow regimes rather than a fixed, time-invariant regulatory minimum flow. This shift is reflected in management of streamflow change created by existing reservoirs and flow diversion structures. With an emphasis on regime-based approaches a new connectivity is demanded between reservoir operations and the resulting downstream flow conditions. Complicating this situation is reservoir management that may be legally limited to flood control and water supply requirements reducing options for supplying downstream needs. This paper proposes an approach to reservoir operation that is based on ecological flow regime concepts. Reservoir operation is guided by six hydrologic indicators selected both to meet the specific flow needs of the local indigenous fish community and to satisfy authorized reservoir operational rules. The approach is based on incorporation of ecology and life history requirements of the fish community in the decision making process to better define and meet flow needs. Optimization using nondominated sorting genetic algorithms provides a basis for reservoir operational schemes that are expected to provide benefit to fish communities downstream while also meeting authorized reservoir storage needs.
\end{abstract}

DOI: $10.1061 /(A S C E) 0733-9496(2009) 135: 6(475)$

CE Database subject headings: Reservoir operation; Ecology; Taiwan; Fish management; Instream flow.

\section{Introduction}

In common practice, reservoir operations are often constrained to meet a limited set of specifications, generally water supply (public, industrial, and agricultural), flood control, or power generation. However, reservoir construction alters river ecosystems (Ward and Stanford 1983). Reservoir effects include the creation of migration discontinuities, alteration of carbon and nutrient cycles, changes sediment transport, and altered flow regimes (Ward 1976; Ligon et al. 1995; Power et al. 1996; Thoms and Sheldon 2002). Altered flow regimes affect water quality, energy sources, physical habitat, and biotic interactions contributing to the loss of ecological integrity in rivers (Poff et al. 1997). Geomorphic changes in channels and floodplains related to flow change make the aquatic ecosystems more vulnerable to other human influences (Brookes 1994). These observations, along with a changing sense of environmental values, have led to an effort to reevaluate the operational rules for reservoirs in order to meet environmental needs through new management approaches.

\footnotetext{
${ }^{1}$ Assistant Professor, Dept. of Hydraulic and Ocean Engineering, National Cheng Kung Univ., No. 1, University Rd., Tainan City, 701, Taiwan (corresponding author). E-mail: jpsuen@mail.ncku.edu.tw

${ }^{2}$ Professor Emeritus, Dept. of Civil and Environmental Engineering, Univ. of Illinois, 205 N. Mathews Ave., Urbana, IL 61801.

${ }^{3}$ Professor, Dept. of Civil and Environmental Engineering, Univ. of Illinois, 205 N. Mathews Ave., Urbana, IL 61801.

${ }^{4}$ Professor, Dept. of Bioenvironmental Systems Engineering, National Taiwan Univ., No. 1, Section 4, Roosevelt Rd., Taipei, 105, Taiwan.

Note. This manuscript was submitted on October 4, 2007; approved on March 11, 2009; published online on October 15, 2009. Discussion period open until April 1, 2010; separate discussions must be submitted for individual papers. This paper is part of the Journal of Water Resources Planning and Management, Vol. 135, No. 6, November 1, 2009. (c)ASCE, ISSN 0733-9496/2009/6-475-483/\$25.00.
}

In the late 1990s, ecologists proposed the use of a natural flow regime approach to address concerns of ecological integrity in water resources management by comparing the discharge, timing, and frequency of natural flow regimes with similar statistics of altered flows (Poff et al. 1997). A natural flow regime is a reasonable ecological target because habitat conditions for indigenous species are produced, sustaining ecological integrity. A natural flow regime provides: (1) a seasonal pattern of flows reflecting historical conditions; (2) timing of extreme events providing needed magnitude and duration to produce historic habitat at times needed in the life cycle of indigenous species; (3) a frequency of return flows that produce floods and droughts to which native species are adapted; (4) a seasonal and annual flow variability that accommodates species needs for reproduction and growth; and (5) a rate of change in flows that does not exceed species capacity for position maintenance or movement to safe locations (Poff et al. 1997). Thus a natural flow regime is the foundation for management based on ecological flows, which is emerging as a new paradigm for multiobjective water resources planning and management. Natural flow regime objectives encourage decision makers to provide flows that protect downstream ecosystems, encouraging the identification of compromise strategies that satisfy the conflicting objectives of both instream flow needs of ecosystems and offstream human water needs (Marchetti and Moyle 2001; Suen and Eheart 2006; Shiau and Wu 2007).

Attempts to achieve more natural flows by modifying reservoir operations are still in their early stages. Most of the past work focused on the effects of generating artificial floods or how water quality (e.g., dissolved oxygen, nutrients, or sediment) can be changed (Barillier et al. 1993; Molles et al. 1995; Rubin et al. 1998). High flow events play an important role in channel/habitat creation and maintenance, but other aspects of flow need to be incorporated into any comprehensive management strategy to 
provide the needed historical magnitude, frequency, duration, timing, and rate-of-change conditions needed for ecosystems (Richter et al. 1996, 1997; Poff et al. 1997). Nevertheless, only a few reservoir management schemes consider using historical hydrologic patterns to incorporate variability into the reservoir operational schemes. The natural flow regime-based management approach described in this paper is more complicated than existing operational schemes, but we assert the proposed approach provides ecological flow benefits because natural flow requirements of indigenous biota are the basis for regime criteria (Koel and Sparks 2002; Suen and Eheart 2006).

Our aim in this paper is to use information from the ecology of indigenous fish to select management options that achieve a useful trade-off between human needs and aquatic ecosystem needs. A multiobjective optimization method is used to find the Pareto set of reservoir operation rules that satisfy both existing water uses that do not consider downstream ecology, and ecosystem needs are defined by predevelopment, or natural, flow conditions. The basis for the optimization is incorporation of the intermediate disturbance hypothesis from ecology (Connell 1978). This hypothesis suggests that ecosystems require periodic disturbance that challenge species and promote more diverse communities of organisms. The most robust assemblage of species in a community will occur when there is significant but not overwhelming disturbance (Connell 1978). The intermediate disturbance idea is incorporated into our optimization procedures through a fuzzy set concept that provides the ecosystem needs objective. Downstream effects of operating rules from the Pareto set are examined to determine how the operation policies change the streamflow patterns and how those patterns affect different fish communities based on the ecological requirements species that is summarized in an autoecology matrix (Suen and Herricks 2006).

\section{Methods}

\section{Study Area and Data}

The Dahan River is located in Taiwan, $40 \mathrm{~km}$ southeast of Taipei in the north of Taiwan. The river originates on Mt. Pingtien and flows $135 \mathrm{~km}$ to the Pacific Ocean on the west side of Taiwan. The Dahan has a drainage area of $1,163 \mathrm{~km}^{2}$. The Shihmen Reservoir, built in 1964, is the most important hydraulic structure in the Dahan River Basin (see Fig. 1). It was built primarily to meet the needs of irrigation, power generation, flood control, and domestic water supply to the Taipei and Taoyuan areas. Its operational rules are based on 36 10-day periods. Every 5-7 years, the reservoir administration reviews water rights for the major water users to evaluate operational changes (Ministry of Economic Affairs 2002).

The average annual precipitation in the Dahan River Basin is $2,900 \mathrm{~mm}$, approximately $68 \%$ of which falls in the wet season, May to October. The average annual streamflow of the Dahan River is $162.65 \mathrm{~cm}$ Although as many as 20 monitoring locations have been active in the basin, many of these stations were abandoned after reservoir construction was completed and only eight flow measurement stations are currently operated. Seven of these 20 stations provide a record longer than 40 years and are not affected by reservoir construction and other hydraulic alterations (e.g., irrigation channels, bank protection, etc.). These undisturbed flow data were used to represent the target of ecological flow regimes.

Historical fish sampling data in the Dahan River Basin are

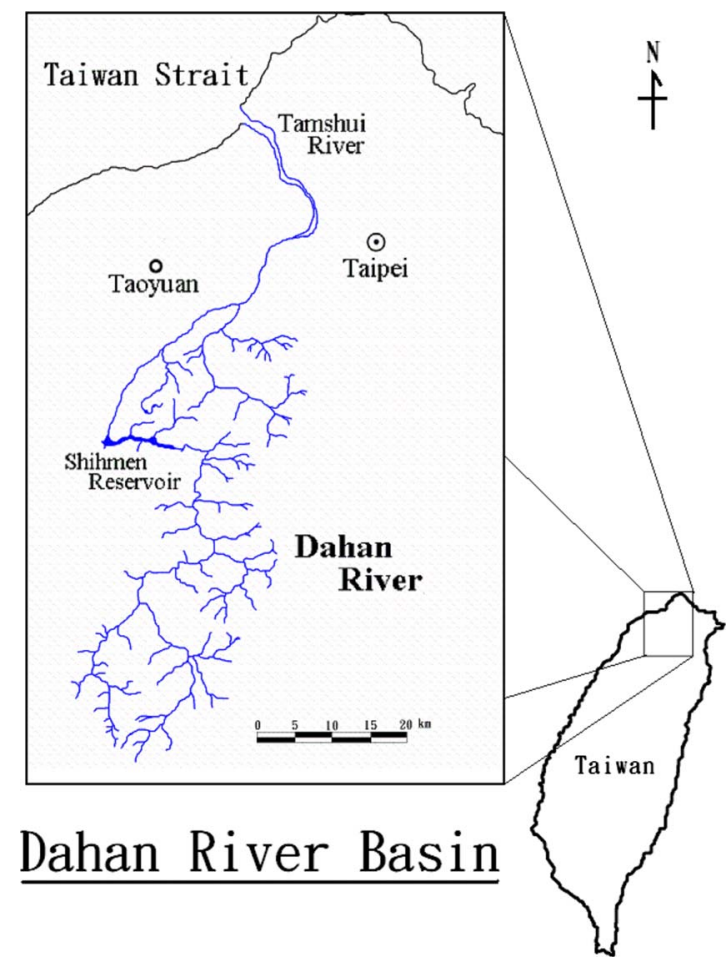

Fig. 1. Shihmen Reservoir and Dahan River Basin

available for 12 locations for two periods in the 1980s and the 1990s (Water Resources Planning Committee 1986; Wang 1998). The 1981 and 1983 data sets are available for ten sampling stations that were sampled six times during this period. These stations bracketed the present position of the reservoir. The 1997 and 1998 data sets are available from seven of the 10 sampling stations that were sampled four times. A total of 32 species were observed in these samples. Table 1 lists the most common fish species divided into three community types. Types include indigenous species (i.e., species native to the area), exotic or invasive species (i.e., typically introduced species), and generalist species (i.e., those species that may be indigenous, but because of their wide tolerance to environmental conditions they are considered "rough" species and are not a target for management). The use of these community types supports an ecological focus in natural flow regime management that favors desirable indigenous or native species.

\section{Multiobjective Approach}

Suen and Eheart (2006) proposed a model that incorporated the ecological flow regime approach for multiobjective reservoir management. In this model both ecosystem and human needs were considered in reservoir operation considerations. The intermediate disturbance hypothesis was incorporated into the analysis using a fuzzy set concept leading to identification of an ecological flow regime as the basis of the ecosystem needs objective. Fuzzy logic theory generally uses a so-called membership function to characterize the degree that a set of quantifiable parameters takes on characteristics that are otherwise ambiguous or "fuzzy" (Zimmermann 1991). In the present case, a membership function is applied to the streamflow data so as to give a high membership score to streamflows that constitute intermediate disturbance [as opposed to light or heavy disturbance (see Fig. 2)]. Thus, the membership values of the intermediate ranges of ecohydrological 
Table 1. Indigenous, Exotic, and Generalist Species in the Dahan River

\begin{tabular}{lcc}
\hline Indigenous species & Exotic species & Generalist species \\
\hline Acrossocheilus paradoxus & Channa sp. & Acrossocheilus formosanus \\
Candidia barbatus & Cyprinus carpio & Carassius auratus \\
Crossostoma lacustre & Gambusia affinis & Cyprinus carpio \\
Hemimyzon formosanum & Hypostomus placostomus & Hypostomus placostomus \\
Leiocassis adiposalis & Oreochromis mossambicus & Oreochromis spp. \\
Microphysogobio brevirostris & Oreochromis spp. & Paracheilognathus himantegus \\
Rhinogobius brunneus & Tilapia zillii & Pseudorasbora parva \\
Zacco pachycephalus & & Rhodeus ocellatus \\
& & Tilapia zillii \\
\hline
\end{tabular}

indicators are close to 1 which represents the management target of ecological flow regimes. The human needs objectives retain domestic, agricultural, and power needs. The general form of the two-objective approach can be written as

$$
\operatorname{Max} Z_{\text {Human }}=\sum_{i} \alpha_{i} \mathrm{SI}_{i}\left(\sum_{i} \alpha_{i}=1 \text { and } 0 \leqslant \mathrm{SI}_{i} \leqslant 1\right)
$$

$\operatorname{Max} Z_{\mathrm{Ecosystem}}=\sum_{j} \beta_{j} \mathrm{EHI}_{j}\left(\sum_{j} \beta_{j}=1\right.$ and $\left.0 \leqslant \mathrm{EHI}_{j} \leqslant 1\right)$

where $\mathrm{SI}_{i}=$ shortage index for domestic, agricultural, and power needs; $\mathrm{EHI}_{i}=$ membership value of ecohydrological indicator for ecosystem needs; and $\alpha$ and $\beta=$ weighting factors.

This multiobjective model allows water managers to find the Pareto optimal frontier between ecosystem and human flow management strategies and to identify operating rules that strike an acceptable balance between these two needs. The essential idea of the Suen and Eheart (2006) model is to maximize the water supply for human needs while maximizing the similarity of managed flow regimes and ecological flow regimes, which are intended to sustain ecosystems. The focus of this paper is on the use of information on fish species that is used to select a small set of ecohydrological indicators that parsimoniously describe important natural system characteristics for optimization while reducing the complexity of model calculations.

\section{Ecohydrological Indicators}

An ecological flow regime incorporates the essential features of a natural flow regime to maintain the structure and the functional integrity of a target community (Herricks and Suen 2004). In a previous study, Suen et al. (2004) identified a suite of ecohydrological indicators, called the Taiwan Ecohydrology Indicator System (TEIS). The TEIS is a group of hydrologic statistics selected to characterize the magnitude, duration, timing, frequency, and rate-of-change based on flow requirements of Taiwan fish species. There are 69 TEIS indicators, however, to facilitate use in water resources policy analysis, a reduced set of indicators is needed to make modeling and analysis tractable.

Ecologically, the best method for selection of a reduced set of TEIS indicators would be determination of the habitat conditions produced by a given discharge for each species of interest considering all life stages of each species. Although there are methods of flow-related habitat assessment [e.g., Bovee (1982)], these methods are typically site specific, are available for a limited number of species, and require extensive additional analysis to address regime requirements. Furthermore, the complexity of attempting this approach for 30 species renders it impossible because the detailed habitat preference data needed for Taiwan fish species are not available. In the absence of detailed habitat preference data, an alternative must be found to link flow information and species presence for use in analysis. The link used in this paper is the autecology matrix (Suen and Herricks 2006). The Taiwan fish autecology matrix assembles ecological requirements of fish species in a table that supports rapid assessment of environmental, ecological, or other requirements of these species. It is possible to conduct a community analysis where the environmental requirements for a group of species can be determined. For example the matrix supports determination that a group of species require stable spawning conditions during the same time period or require maintenance of pools or riffle areas. These requirements can be translated into flow needs based on watershed conditions. An autecology matrix analysis allows relatively easy identification of the environmental and ecological requirements of fish communities (Suen and Herricks 2006). In the Dahan River, information from the autecology matrix analysis was used to identify expected responses of indigenous species to flow regimes provided by modified reservoir operational rules.

\section{Selection of Indicators}

To support the multiobjective analysis of reservoir operation a reduced set of hydrologic indicators was needed. Based on the autecology matrix (Suen and Herricks 2006), it was possible to identify conditions favorable to indigenous species. The conditions selected also produced conditions unfavorable for exotic, or generalist, species (Moyle and Light 1996). For instance, indig-

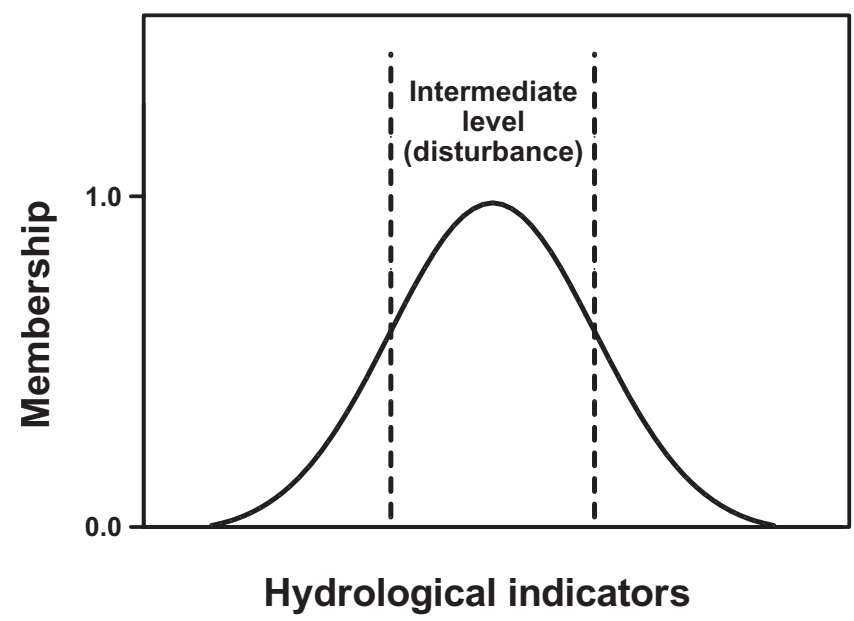

Fig. 2. Fuzzy membership function to represent the intermediate disturbance concept to ecological flow regime 
Table 2. Selected Ecohydrological Indicators for Reservoir Operational Strategy

Ecohydrological indicator

Coefficient of efficiency of the yearly trend of hydrograph

Wet season 3-day maximum

Dry season 3-day maximum

Number of high flow events with in each dry season

Mean duration of low flow events

Mean of all positive differences between consecutive values in the wet season (rising rate)
Ecological translation

Magnitude of streamflow supporting the required physical habitat environmental factors

Typhoon-season high flow and change in substrate composition

Spawning-season high flow and change in substrate composition

Spawning-season changes in flow and pool/riffle availability

Required spawning environment suitability

Changes in flow velocity and substrate composition enous species require flows typical of high discharge periods during typhoons (hurricanes) and extended low flows during the dry season (Bernardo et al. 2003). Exotic species are poorly adapted to high discharges so a return to historical flow conditions with periodic high discharge conditions would be expected to benefit indigenous species (Tew et al. 2002, Matthews 1986). Therefore, the indicator "wet season 3-day maximum" was used to establish a possible rule for reservoir operation that would mimic typhoonrelated flow events that would be expected to benefit downstream indigenous species.

Other hydrologic conditions that, if produced by reservoir management procedures, would be expected to benefit indigenous species include the "dry season 3-day maximum," the "number of high flow events within each dry season," and the "mean of all positive differences between consecutive values in the wet season (rising rate)." These indicators are related to the increased stage and flow velocity and can be related to spawning based on general habitat conditions and habitat stability. For example increased discharge produces deeper pools, higher average velocity in pools, and expansion of habitat in riffle areas. Because indigenous species tend to be riffle spawners with eggs attached to coarse substrates not moved by higher flows, these species are at an advantage. Correspondingly, exotic species tend to be bottomnesting, preferring low to no velocity in pool areas (Suen 2005). Although the spawning periods of both indigenous and exotic species are similar, the coarse substrate habitat selected by indigenous species is less susceptible to damage by stage or velocity changes than the fine substrate habitats commonly used by exotic species. The mean duration of low flow events was used to identify reduced riffle area and the length of time low velocity pools.

The final indicator "mean streamflow for each 10-day period" is related to flow magnitude relationships to habitat. High flows maintain stream channel conditions (Leopold et al. 1964; Ward and Trimble 2004) producing stream habitats that connect the channel with riparian areas (Hupp and Osterkamp 1996). An alternative indicator was the use of "the coefficient of efficiency of the yearly trend of hydrograph" which takes into account both mean streamflow for 10-day period and "timing of annual extreme conditions." This coefficient shows how close the yearly hydrograph is to an ideal hydrograph (a natural flow regime target). It can be written as

$$
\mathrm{CE}=1-\frac{\sum_{i=1}^{36}\left(Q_{i}-\hat{Q}_{i}\right)^{2}}{\sum_{i=1}^{36}\left(Q_{i}-\bar{Q}\right)^{2}}
$$

where $\hat{Q}_{i}=10$-day mean of the preconstruction period streamflow; $Q_{i}=$ observed 10-day streamflow; and $\bar{Q}=$ mean of the observed 10-day streamflow.
This approach of translating hydrologic characteristics into habitat properties provides a reduced set of ecohydrological indicators that produce habitats favorable for indigenous species. The following six indicators comprise the reduced set selected for optimizing reservoir operation to enhance native or indigenous fish species: (1) "coefficient of efficiency of the yearly trend of hydrograph"; (2) wet season 3-day maximum; (3) dry season 3-day maximum; (4) number of high flow events within each dry season; (5) mean duration of low flow events; and (6) mean of all positive differences between consecutive values in the wet season (rising rate) (see Table 2). The operational goal in pursuit of the ecological objective is to maximize the similarity between the downstream streamflow characteristics produced after reservoir construction and the natural flow regime characteristics (Suen and Eheart 2006; Suen and Herricks 2009).

\section{Results and Discussion}

A nondominated sorting genetic algorithm program (Deb et al. 2002) with a population size of 1,000 was used to solve the multiobjective reservoir operation problem. The improvement of nondominated solutions is observed to plateau after 300 generations. The algorithm is stopped after 400 generations. There are 84 solutions for the two-objective functions in the Pareto front (see Fig. 3 ) and each of these 84 solutions represents a storage rule curve for reservoir operation. The decision variables are the storage levels of the 36 10-day periods, which constitute the storage rule curve for reservoir operation. We can choose different storage curves from the Pareto front solutions. These storage rule curves provide the guidance for managers to adjust the water level in the reservoir throughout the year in pursuit of the two objectives. The solutions near Point A represent emphasis on the ecosystem objective, while those near Point $B$ represent emphasis on the human needs objective.

A hydrologic scenario is provided by daily streamflow data for calculation of each hydrologic indicator. For each effective storage solution on the Pareto front, 39 hydrologic scenarios are used to determine the ecological flow characteristics related to a specific operation storage curve. Fig. 4 shows the cumulative frequency curves of 84 effective storage solutions on the Pareto front for the six ecohydrological indicator membership values. A higher membership value represents an intermediate range of the hydrologic disturbance which is assumed to be better for aquatic ecosystems (Suen and Eheart 2006). In the wet season, about $20 \%$ of hydrologic scenarios can provide high 3-day maximum membership values [Fig. 4(b)]. But in the dry season, most 3-day maximum membership values are low [Fig. 4(c)]. In the wet season, the reservoir must release a large amount of water during strong typhoon events because the effective storage has reached the designed storage curve. It is then easier to achieve a higher mem- 


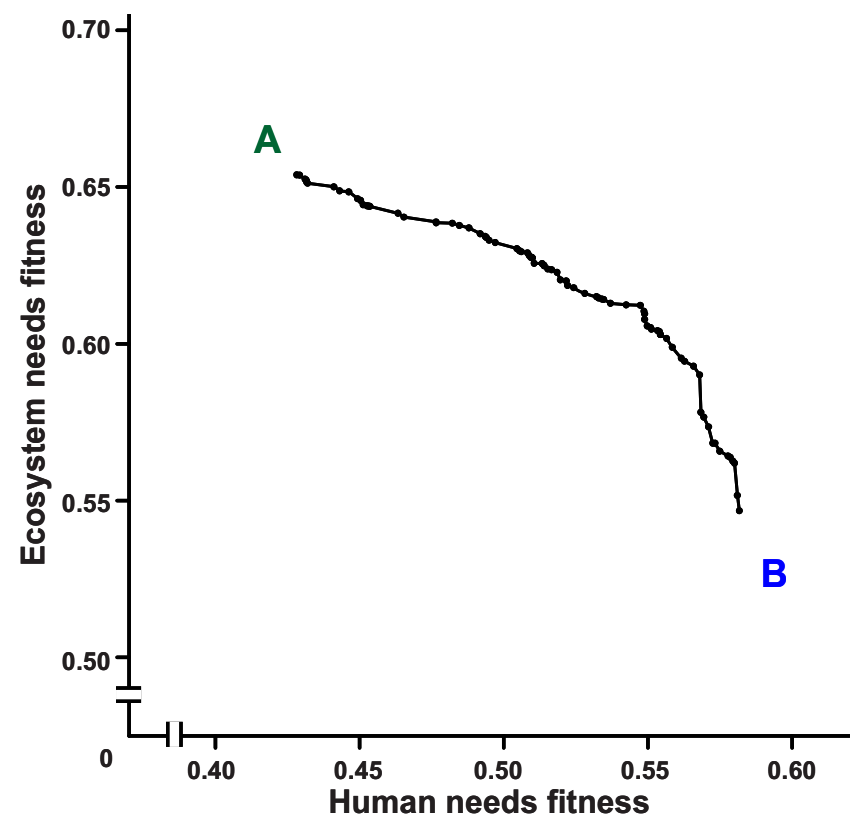

Fig. 3. Pareto front of the ecosystem needs and human needs objective. Point A has the highest ecosystem needs objective fitness; point $\mathrm{B}$ has the highest human needs objective fitness.

bership value during this period. In the dry season, the reservoir stores most of the inflow to reach the designed storage curve, so the 3-day maximum value would be lower than it was before the reservoir was built. The membership value would be lower under those circumstances because of the reservoir operation.

Although approximately $70 \%$ of hydrologic scenarios provide similar frequency levels of mean duration of low flow events as the 84 effective storage solutions on the Pareto front [Fig. 4(e)], the other $30 \%$ provide a different mean duration of low flow events and those low-membership-value scenarios may pose a threat to aquatic ecosystems. Only $20-30 \%$ of hydrologic scenarios provide high membership values for wet season rising rate, which indicates that by storing water in the wet season the reservoir operation results in the streamflow rising rate lower than that which is needed to meet an ecological flow regime objective [Fig. 4(f)].

This analysis suggests that reservoir operation affects six ecohydrological indicators simultaneously but to different degrees. A particularly effective storage solution may favor one or two indicators, but disfavor others. A parsimonious way of assessing these trade-offs is via correlation coefficients between the ecohydrological indicator membership values from the Pareto front effective storage solution operations, shown in Table 3. Dry season 3-day maximum and wet season rising rate reveal the highest correlation, while other correlations are relatively small for all 84 solutions on the Pareto front (Table 3). The table shows that each ecohydrological indicator is unique and important. The eight solutions closest to two ends (Points A and B) on the Pareto front are also selected to compare differences between emphasizing human and ecosystem needs (see Table 3). The correlations between (1) the number of high flow events in the dry season and wet season 3-day maximum; (2) coefficient of efficiency and mean duration of low flow events; and (3) number of high flow events in the dry season and dry season 3-day maximum membership values reveal the three largest differences in correlation $(0.3415$, 0.2109 , and 0.2009 , respectively) between the near-A and near-B solutions.

Table 4 shows the probabilities of other indicator levels when

Table 3. Correlation Coefficients between the Ecohydrological Indicator Membership Values from the Pareto Front Effective Storage Solution Operations

\begin{tabular}{|c|c|c|c|c|c|c|}
\hline & $\mathrm{COE}$ & W3Max & D3Max & DNHF & MDLF & WRR \\
\hline \multicolumn{7}{|c|}{ All 84 solutions on the Pareto front } \\
\hline $\mathrm{COE}$ & 1.0000 & & & & & \\
\hline W3Max & 0.1033 & 1.0000 & & & & \\
\hline D3Max & -0.0517 & 0.0315 & 1.0000 & & & \\
\hline DNHF & 0.0164 & -0.1664 & 0.0365 & 1.0000 & & \\
\hline MDLF & 0.3460 & 0.2039 & -0.2360 & -0.1458 & 1.0000 & \\
\hline WRR & 0.0018 & 0.0737 & 0.6659 & -0.0177 & -0.3324 & 1.0000 \\
\hline
\end{tabular}

The eight solutions closest to Point A on the Pareto front

\begin{tabular}{|c|c|c|c|c|c|c|}
\hline $\mathrm{COE}$ & 1.0000 & & & & & \\
\hline W3Max & 0.0256 & 1.0000 & & & & \\
\hline D3Max & -0.0557 & -0.0102 & 1.0000 & & & \\
\hline DNHF & 0.0129 & -0.3387 & 0.0933 & 1.0000 & & \\
\hline MDLF & 0.4280 & 0.1553 & -0.1642 & -0.3502 & 1.0000 & \\
\hline WRR & -0.0355 & 0.0186 & 0.6490 & 0.0367 & -0.2276 & 1.0000 \\
\hline \multicolumn{7}{|c|}{ The eight solutions closest to Point B on the Pareto front } \\
\hline $\mathrm{COE}$ & 1.0000 & & & & & \\
\hline W3Max & 0.1745 & 1.0000 & & & & \\
\hline D3Max & -0.0311 & -0.0698 & 1.0000 & & & \\
\hline DNHF & 0.1141 & 0.0028 & -0.1076 & 1.0000 & & \\
\hline MDLF & 0.2171 & 0.3296 & -0.1788 & -0.1946 & 1.0000 & \\
\hline WRR & 0.0693 & 0.0322 & 0.6444 & -0.0979 & -0.2037 & 1.0000 \\
\hline
\end{tabular}

Note: COE: coefficient of efficiency; W3Max: wet season 3-day maximum; D3Max: dry season 3-day maximum; DNHF: number of high flow events in the dry season; MDLF: mean duration of low flow events; and WRR: wet season rising rate. 


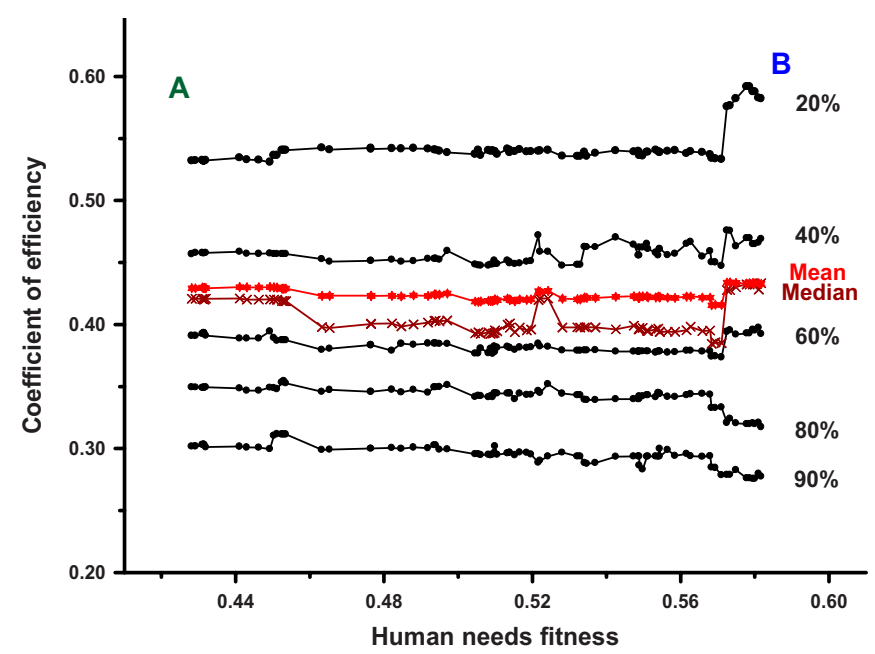

(a)

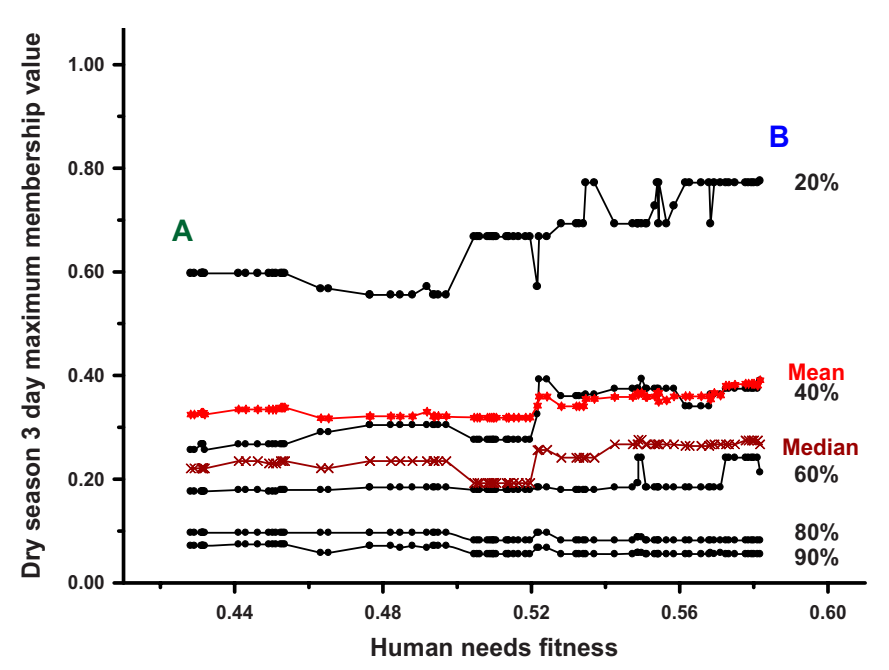

(c)

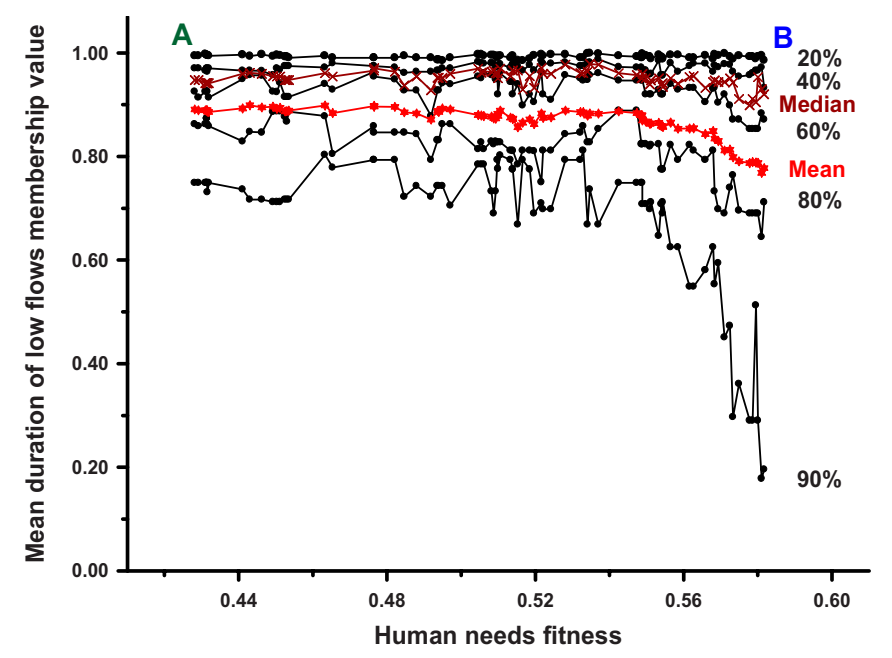

(e)

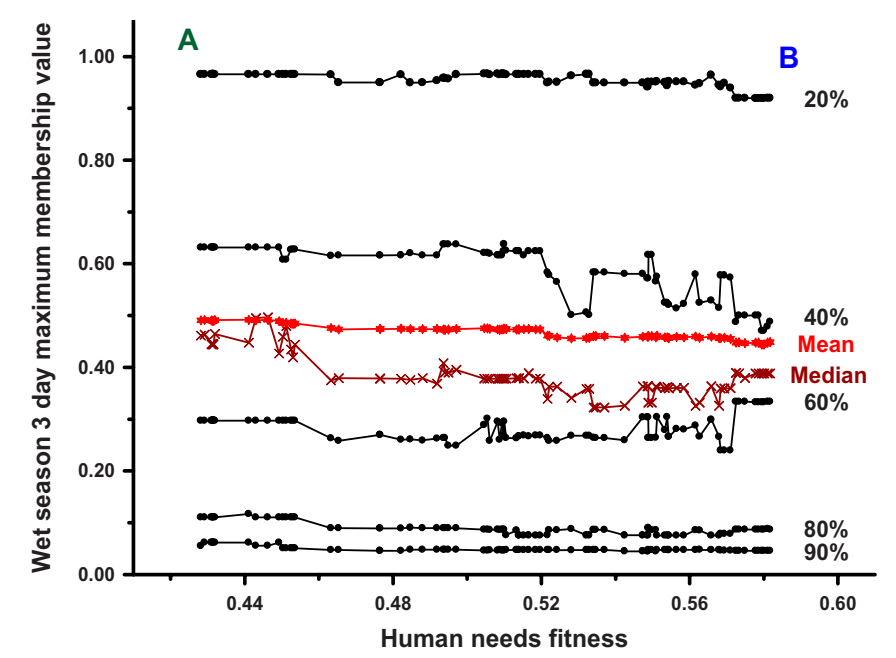

(b)

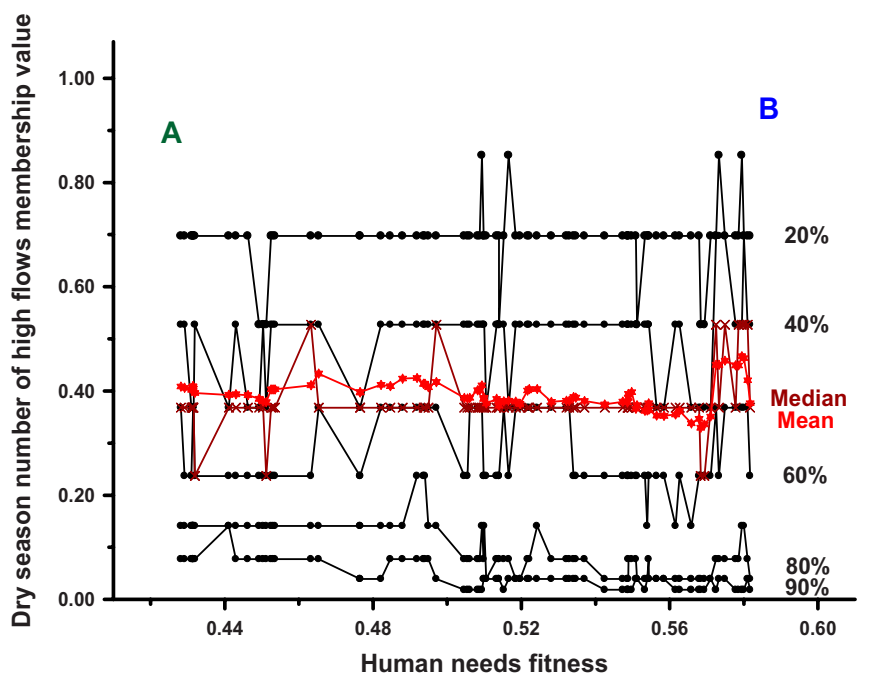

(d)

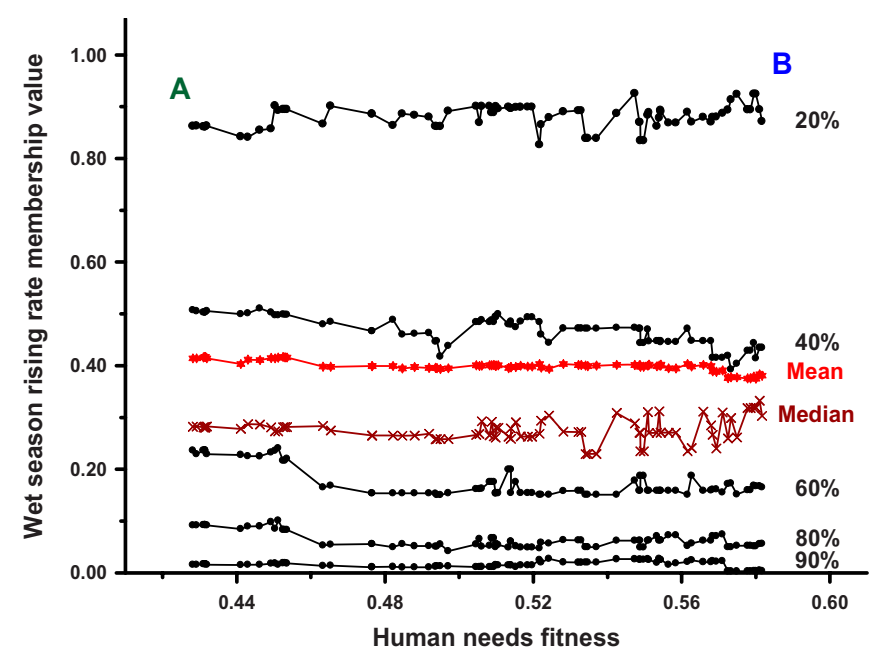

(f)

Fig. 4. Frequency levels of (a) coefficient of efficiency; (b) wet season 3-day maximum membership value; (c) dry season 3-day maximum membership value; (d) number of high flow events in the dry season membership value; (e) mean duration of low flow events membership value; and (f) wet season rising rate membership value from the Pareto front effective storage solutions 
Table 4. Conditional Probabilities (All in Percent) between the Ecohydrological Indicator Membership Values from the Pareto Front Effective Storage Solutions

The eight solutions closest to Point A on the Pareto front

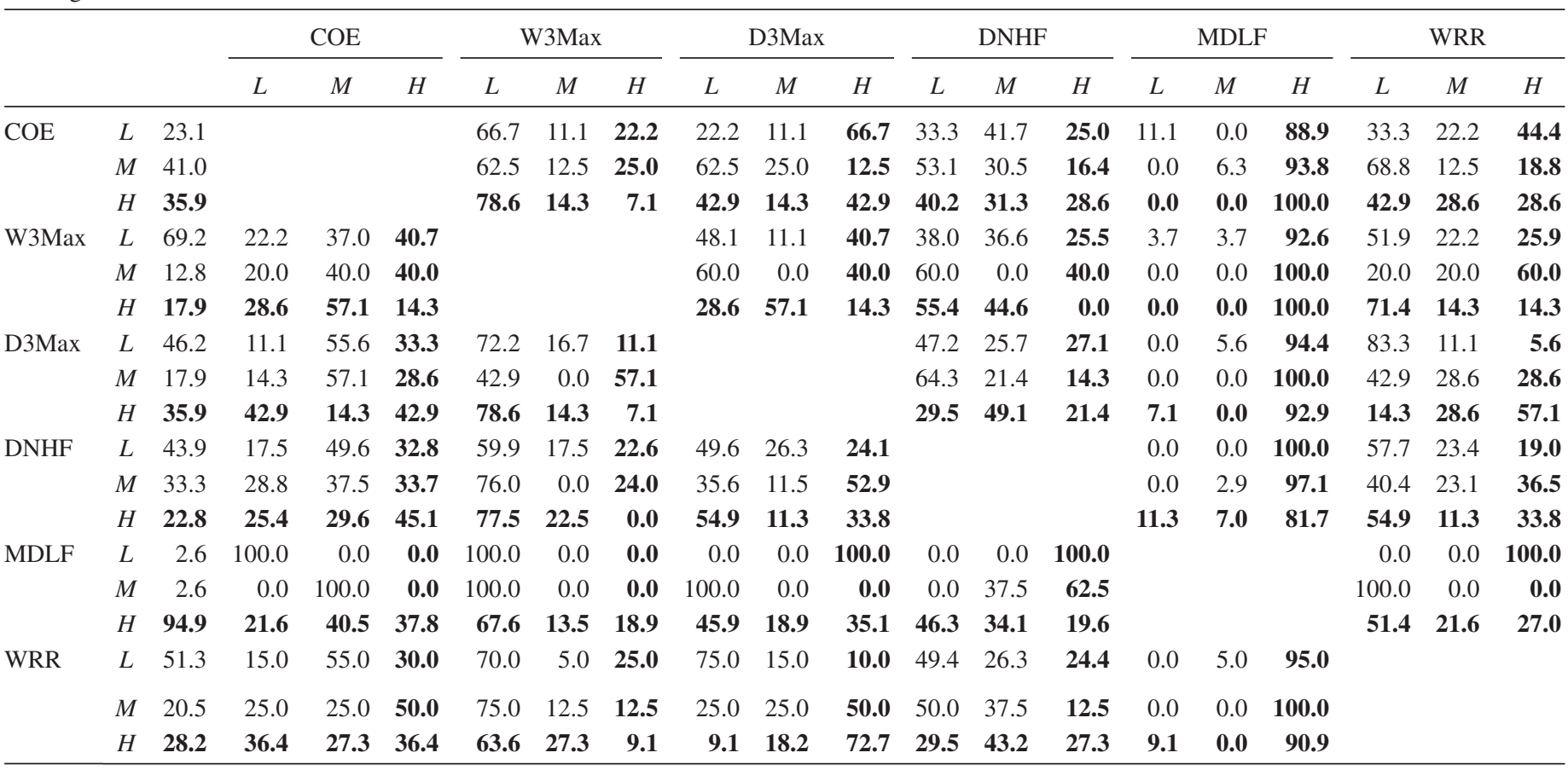

The eight solutions closest to Point B on the Pareto front

\begin{tabular}{|c|c|c|c|c|c|c|c|c|c|c|c|c|c|c|c|c|c|c|c|c|}
\hline & & & \multicolumn{3}{|c|}{$\mathrm{COE}$} & \multicolumn{3}{|c|}{ W3Max } & \multicolumn{3}{|c|}{ D3Max } & \multicolumn{3}{|c|}{ DNHF } & \multicolumn{3}{|c|}{ MDLF } & \multicolumn{3}{|c|}{ WRR } \\
\hline & & & $L$ & $M$ & $H$ & $L$ & $M$ & $H$ & $L$ & $M$ & $H$ & $L$ & $M$ & $H$ & $L$ & $M$ & $H$ & $L$ & $M$ & $H$ \\
\hline \multirow[t]{3}{*}{$\mathrm{COE}$} & $L$ & 25.6 & & & & 50.0 & 30.0 & 20.0 & 20.0 & 40.0 & 40.0 & 45.0 & 26.3 & 28.8 & 13.8 & 7.5 & 78.8 & 50.0 & 10.0 & 40.0 \\
\hline & $M$ & 43.6 & & & & 64.7 & 11.8 & 23.5 & 55.9 & 20.6 & 23.5 & 45.6 & 26.5 & 27.9 & 14.0 & 11.0 & 75.0 & 65.4 & 21.3 & 13.2 \\
\hline & $H$ & 30.8 & & & & 50.0 & 8.3 & 41.7 & 41.7 & 25.0 & 33.3 & 25.0 & 21.9 & 53.1 & 8.3 & 0.0 & 91.7 & 33.3 & 43.8 & 22.9 \\
\hline \multirow[t]{3}{*}{ W3Max } & $L$ & 56.4 & 22.7 & 50.0 & 27.3 & & & & 45.5 & 18.2 & 36.4 & 35.8 & 30.1 & 34.1 & 19.9 & 8.0 & 72.2 & 55.1 & 26.7 & 18.2 \\
\hline & $M$ & 15.4 & 50.0 & 33.3 & 16.7 & & & & 16.7 & 66.7 & 16.7 & 54.2 & 16.7 & 29.2 & 0.0 & 4.2 & 95.8 & 50.0 & 0.0 & 50.0 \\
\hline & $H$ & 28.2 & 18.2 & 36.4 & 45.5 & & & & 50.0 & 22.7 & 27.3 & 37.5 & 19.3 & 43.2 & 3.4 & 5.7 & 90.9 & 45.5 & 36.4 & 18.2 \\
\hline \multirow[t]{3}{*}{ D3Max } & $L$ & 42.3 & 12.1 & 57.6 & 30.3 & 60.6 & 6.1 & 33.3 & & & & 25.0 & 36.4 & 38.6 & 12.1 & 1.5 & 86.4 & 81.8 & 18.2 & 0.0 \\
\hline & $M$ & 26.9 & 38.1 & 33.3 & 28.6 & 38.1 & 38.1 & 23.8 & & & & 59.5 & 14.3 & 26.2 & 0.0 & 2.4 & 97.6 & 34.5 & 36.9 & 28.6 \\
\hline & $H$ & 30.8 & 33.3 & 33.3 & 33.3 & 66.7 & 8.3 & 25.0 & & & & 40.6 & 18.8 & 40.6 & 22.9 & 17.7 & 59.4 & 25.0 & 25.0 & 50.0 \\
\hline \multirow[t]{3}{*}{ DNHF } & $L$ & 39.1 & 29.5 & 50.8 & 19.7 & 51.6 & 21.3 & 27.0 & 27.0 & 41.0 & 32.0 & & & & 6.6 & 9.0 & 84.4 & 41.0 & 31.1 & 27.9 \\
\hline & $M$ & 25.0 & 26.9 & 46.2 & 26.9 & 67.9 & 10.3 & 21.8 & 61.5 & 15.4 & 23.1 & & & & 14.1 & 3.8 & 82.1 & 56.4 & 26.9 & 16.7 \\
\hline & $H$ & 35.9 & 20.5 & 33.9 & 45.5 & 53.6 & 12.5 & 33.9 & 45.5 & 19.6 & 34.8 & & & & 17.0 & 6.3 & 76.8 & 59.8 & 17.9 & 22.3 \\
\hline \multirow[t]{3}{*}{ MDLF } & $L$ & 12.2 & 28.9 & 50.0 & 21.1 & 92.1 & 0.0 & 7.9 & 42.1 & 0.0 & 57.9 & 21.1 & 28.9 & 50.0 & & & & 21.1 & 26.3 & 52.6 \\
\hline & $M$ & 6.7 & 28.6 & 71.4 & 0.0 & 66.7 & 9.5 & 23.8 & 9.5 & 9.5 & 81.0 & 52.4 & 14.3 & 33.3 & & & & 52.4 & 23.8 & 23.8 \\
\hline & $H$ & 81.1 & 24.9 & 40.3 & 34.8 & 50.2 & 18.2 & 31.6 & 45.1 & 32.4 & 22.5 & 40.7 & 25.3 & 34.0 & & & & 56.1 & 25.3 & 18.6 \\
\hline \multirow[t]{3}{*}{ WRR } & $L$ & 51.6 & 24.8 & 55.3 & 19.9 & 60.2 & 14.9 & 24.8 & 67.1 & 18.0 & 14.9 & 31.1 & 27.3 & 41.6 & 5.0 & 6.8 & 88.2 & & & \\
\hline & $M$ & 25.3 & 10.1 & 36.7 & 53.2 & 59.5 & 0.0 & 40.5 & 30.4 & 39.2 & 30.4 & 48.1 & 26.6 & 25.3 & 12.7 & 6.3 & 81.0 & & & \\
\hline & $H$ & 23.1 & 44.4 & 25.0 & 30.6 & 44.4 & 33.3 & 22.2 & 0.0 & 33.3 & 66.7 & 47.2 & 18.1 & 34.7 & 27.8 & 6.9 & 65.3 & & & \\
\hline
\end{tabular}

Note: For COE values: $L$ is less than $0.35, M$ is between 0.35 and 0.5 , and $H$ is larger than 0.5. For W3Max, D3Max, DNHF, MDLF, and WRR membership values: $L$ is less than $0.3333, M$ is between 0.3333 and 0.6667 , and $H$ is larger than 0.6667 . Bold numbers represent high membership values.

the probability of an ecohydrological indicator is known. For example, when selecting the eight solutions closest to Point A, $17.9 \%$ of wet season 3-day maximum membership values are high $(\mathrm{H})$. When the wet season 3-day maximum membership value is high, 55.4, 44.6, and $0 \%$ of the number of high flow events in the dry season membership values are low (L), medium $(\mathrm{M})$, and high $(\mathrm{H})$, respectively. On the other hand, when selecting the eight solutions closest to Point B, $28.2 \%$ of wet season 3-day maximum membership values are high, and 37.5, 19.3, and $43.2 \%$ of the number of high flow events in the dry season mem- bership values are low (L), medium $(\mathrm{M})$, and high $(\mathrm{H})$, respectively. It shows that when considering the solutions favorable to human needs (close to Point B), the probability is high that the number of high flow events in the dry season and the wet season 3-day maximum membership values are both high. This is important when considering the solutions favorable to ecosystem needs (close to Point A). It is important to recognize that within any one group of species, the species specific responses to environmental conditions may vary. This analysis suggests that although not all species' specific needs will be met, needs can be preferentially 
met for indigenous species as a group by controlling flows to produce near natural conditions for these two ecohydrological indicators.

\section{Ties to Ecological Habitat}

Although none of the 84 solutions from the Pareto front set are dominated by any other solution when both human needs and ecosystem needs objectives are considered, each solution still produces different outcomes for both human and ecosystem objectives. However, further scrutiny of all 84 Pareto front solutions with regard to the six ecohydrological indicators reveals possible attractive management options that may protect downstream fish communities while acceptably meeting human needs. At the same time, there are negative effects that are hiding just below the surface of some of the 84 solutions. For example, although only $30-40 \%$ of the hydrologic scenarios may provide significantly different mean duration of low flow events based on which solution is chosen from the Pareto front [Fig. 4(e)], the preferred habitat unit, habitat cover, and some water quality parameters may be affected depending on which storage rule curve is used to operate the reservoir. Longer low flow durations downstream may reduce riffle habitat and create more shallow pools that favor exotic species. Water quality (e.g., dissolved oxygen and salinity) is expected to be worse under low flow conditions and will threaten the survival of indigenous species that do not tolerate poor water quality. Although the differences of 3-day maximum membership values of the same frequency level are relatively small when the reservoir operates under the 84 effective storage solutions on the Pareto front [Figs. 4(b and c)], smaller 3-day maximum values are expected both in the dry season and the wet season. Reduction in the high flow events by reservoir operation is known to influence channel habitat (Ligon et al. 1995; Bernardo et al. 2003) often leading to reduced habitat complexity. The simplified channels lose some important habitats for indigenous species, such as spawning gravels, which may be buried by silt and not restored by periodic high flows. Another issue is general habitat availability. If the natural frequency of channel forming events is changed, spawning of indigenous species is likely to occur on a reduced scale because of reduced riffle habitat areas, and deposition, scour, and substrate movement may compromise spawning by burying or flushing away eggs. With a reduction of the frequency of high flow events exotic species can maintain their population because spawning success is improved when nests are not scoured by high flows. To favor indigenous species, designed high flow events should be incorporated in the operational strategy.

Since only $20-30 \%$ hydrologic of scenarios can provide high membership values of wet season rising rate [Fig. 4(f)], the construction of reservoirs will produce altered flow conditions that are difficult to mitigate. This finding suggests that post-reservoir construction there is only a $20-30 \%$ chance that the downstream flow regimes could provide similar velocity and substrate conditions to those produced by natural flows in the wet season. Because the life span of most indigenous species is about three years (Suen et al. 2004) it is unlikely that populations can be sustained when good conditions might be expected only every 4-5 years (based on 20-30\% chance of these conditions recurring). Unless these types of conditions can be mitigated by other enhancements to indigenous species (e.g., stocking), the loss of indigenous species would be expected. It is clear that, barring such strategies, indigenous species are threatened by reservoir construction and their populations may eventually decrease.
Each ecohydrological indicator can be used to identify management procedures that would promote better conditions for the indigenous species group through a favorable set of storage rule curves. Although emphasis on a specific indicator may produce benefits, to assure fish community success considering all uncertainties, the six ecohydrological indicators should be used together to address ecological flow regimes needs that will benefit the indigenous species community. It is impossible to provide high membership values simultaneously for six ecohydrological indicators in 1 year (refer to Table 4) by using any particular storage rule curves. It is also impossible to increase indigenous species population in one year by using any of the storage rule curves to operate reservoirs. The benefit of an ecological flow regime approach is that it accounts for good and bad years and produces management schemes that will provide for the longterm sustainability of target groups. The regime-based approach for operating reservoirs needs time to provide a better environment for aquatic ecosystems. In one year, it may provide one or two higher membership values of ecohydrological indicators, and in another year, it may provide higher membership values of other indicators. To assure success in any management program, water resources managers and engineers should work closely with biologists to monitor the fish communities. This monitoring effort should be based on ecological time scales that assure population success. An adaptive management strategy could reduce the impact of reservoir operation on fish communities, but it should be emphasized that such a strategy must be designed in cognizance of the goals of achieving long-term averages of its objectives. A strategy that attempts to adapt too quickly risks over-adapting and instability.

\section{Conclusions}

The adoption of an ecological flow regime approach is possible for existing reservoirs through modified storage rule curves. Although reservoir operation is rarely designed to address downstream ecosystem needs, it is possible using the approach described in this paper to develop adaptive strategies to enhance indigenous fish communities downstream from reservoirs in Taiwan. The key to the development of new procedures is the incorporation of information on the environmental requirements of indigenous species that can be met by influencing the hydrology in downstream areas. Using ecological requirements of targeted indigenous species groups it was possible to identify the likely effect on each group to ecohydrological indicators selected from the Taiwan Ecohydrology Indicator System. A reduced set of indicators was shown to provide needed information related to indigenous species sustainability. These indicators were used in a model that allowed evaluation of trade-offs through a Paretooptimal frontier that allows reservoir managers to choose the relative emphasis to be placed on ecosystem versus human needs. This model also identified the critical need to consider reservoir operations over a long term, providing for the needs of the indigenous fish community through adaptation of operational schemes to meet ecological requirements of the fish community. Although reservoir operation may cause hydrologic alteration, it is still possible to satisfy human water needs while creating ecological flow regimes that can maintain, if not benefit, an indigenous species community. The results show that the effects on environmental indicators are determined by how the reservoir is operated. It should be recognized, however, that such a regime-based approach is to be considered a multiyear management strategy, and 
that, while incorporating natural flow variability into reservoir release rules would provide long-term benefit to aquatic ecosystems, improvements in ecological integrity are not necessarily expected to be immediate.

\section{Acknowledgments}

The writers gratefully acknowledge the research support of, and data supplied by, the Water Resources Agency, Taiwan and the research support by the Taiwan National Science Council under Contract No. 96-2221-E-006-264-MY3. Any opinions, findings, and conclusions or recommendations expressed in this publication are those of the writers and do not necessarily reflect the views of the funding agency.

\section{References}

Barillier, A., Garnier, J., and Coste, M. (1993). "Experimental reservoir water release: Impact on the water quality on a river $60 \mathrm{~km}$ downstream (Upper Seine River, France)." Water Res., 27(4), 635-643.

Bernardo, J. M., Ilheu, M., Matono, P., and Costa, A. M. (2003). "Interannual variation of fish assemblage structure in a Mediterranean River: Implications of streamflow on the dominance of native or exotic species." River Res. Appl., 19(5-6), 521-532.

Bovee, K. D. (1982). "A guide to stream habitat analysis using instream flow incremental methodology, instream flow information." Instream Flow Information Paper No. 12, U.S. Fish and Wildlife Service, Fort Collins, Colo.

Brookes, A. (1994). "River channel change." The river handbook, P. Calow and G. E. Petts, eds., Vol. 2, Wiley, New York, 55-75.

Connell, J. H. (1978). "Diversity in tropical rain forests and coral reefs." Science, 199, 1302-1310.

Deb, K., Pratap, A., Agarwal, S., and Meyarivan, T. (2002). "A fast and elitist multiobjective genetic algorithm: NSGA-II." IEEE Trans. Evol. Comput., 6(2), 182-197.

Herricks, E. E., and Suen, J. P. (2004). "Ecological flow regime analysis: Developing ecohydrological indictors for Taiwan." Proc., 14th $\mathrm{Hy}$ draulic Engineering Conf., National Chiao Tung Univ., Hsin Chu, Taiwan, 32-44.

Hupp, C. R., and Osterkamp, W. R. (1996). "Riparian vegetation and fluvial geomorphic processes." Geomorphology, 14, 277-295.

Koel, T. M., and Sparks, R. E. (2002). "Historical patterns of river stage and fish communities as criteria for operations of dams on the Illinois River." River Res. Appl., 18(1), 3-19.

Leopold, L. B., Wolman, M. G., and Miller, J. P. (1964). Fluvial processes in geomorphology, Freeman, San Francisco.

Ligon, F. K., Dietrich, W. E., and Trush, W. J. (1995). "Downstream ecological effects of dams." Bioscience, 45(3), 183-192.

Marchetti, M. P., and Moyle, P. B. (2001). "Effects of flow regime on fish assemblages in a regulated California stream." Ecol. Appl., 11(2), 530-539.

Matthews, W. J. (1986). "Fish faunal structure in an Ozark stream: Stability, persistence and a catastrophic flood." Copeia, 1986, 388-397.

Ministry of Economic Affairs. (2002). Shihmen Reservoir operation rules, Ministry of Economic Affairs, Taipei (in Chinese).

Molles, M. C., Crawford, C. S., and Ellis, L. M. (1995). "Effects of an experimental flood on litter dynamics in the middle Rio Grande riparian ecosystem." Regul. Rivers Res. Manage., 11(3-4), 275-281.

Moyle, P. B., and Light, T. (1996). "Fish invasions in California: Do biotic factors determine success?" Ecology, 77, 1666-1670.

Poff, N. L., et al. (1997). "The natural flow regime." Bioscience, 47(11), 769-784.

Power, M. E., Dietrich, W. E., and Finlay, J. C. (1996). "Dams and downstream aquatic biodiversity: Potential food web consequences of hydrologic and geomorphic change." Environ. Manage. (N. Y.), 20(6), 887-895.

Richter, B. D., Baumgartner, J. V., Powell, J., and Braun, D. P. (1996). “A method for assessing hydrologic alteration within ecosystems." Conserv. Biol., 10(4), 1163-1174.

Richter, B. D., Baumgartner, J. V., Wigington, R., and Braun, D. P. (1997). "How much water does a river need?" Freshwater Biol., 37(1), 231-249.

Rubin, D. M., Nelson, J. M., and Topping, D. J. (1998). "Relation of inversely graded deposits to suspended-sediment grain-size evolution during the 1996 flood experiment in Grand Canyon." Geology, 26(2), 99-102.

Shiau, J. T., and Wu, F. C. (2007). "Pareto-optimal solutions for environmental flow schemes incorporating the intra-annual and interannual variability of the natural flow regime." Water Resour. Res., 43(6), W06433.

Suen, J. P. (2005). "Ecologically based methods for multi-objective water resources management in Taiwan." Ph.D. dissertation, Univ. of Illinois, Urbana, Ill.

Suen, J. P., and Eheart, J. W. (2006). "Reservoir management to balance ecosystem and human needs: Incorporating the paradigm of the ecological flow regime." Water Resour. Res., 42(3), W03417.

Suen, J. P., and Herricks, E. E. (2006). "Investigating the causes of fish community change in the Dahan River (Taiwan) using an autecology matrix." Hydrobiologia, 568, 317-330.

Suen, J. P., and Herricks, E. E. (2009). "Developing fish community based ecohydrological indicators for water resources management in Taiwan." Hydrobiologia, 625, 223-234.

Suen, J. P., Herricks, E. E., and Eheart, J. W. (2004). "Ecohydrological indicators for rivers of northern Taiwan." World Water \& Environmental Resources Congress 2004, ASCE/EWRI, Salt Lake City.

Tew, K. S., Han, C. C., Chou, W. R., and Fang, L. S. (2002). "Habitat and fish fauna structure in a subtropical mountain stream in Taiwan before and after a catastrophic typhoon." Environ. Biol. Fishes, 65(4), 457-462.

Thoms, M. C., and Sheldon, F. (2002). “An ecosystem approach for determining environmental water allocations in Australian dry land river systems: the role of geomorphology." Geomorphology, 47(2-4), $153-168$

Wang, H. C. (1998). "Biomonitoring analysis of fish in Tamshui River." Annual Scientific Rep. Prepared for National Institute of Environmental Analysis 7, Environmental Protection Administration, 181-212 (in Chinese).

Ward, A. D., and Trimble, S. W. (2004). Environmental hydrology, Lewis, Boca Raton, Fla.

Ward, J. V. (1976). "Effects of flow patterns below large dams on stream benthos: A review." Instream Flow Needs Symp., J. F. Orsborn and C. H. Allman, eds., Vol. II, American Fisheries Society, Bethesda, Md., 235-253.

Ward, J. V., and Stanford, J. A. (1983). "The serial discontinuity concept of lotic ecosystems." Dynamics of lotic ecosystems, T. D. Fontaine and S. M. Bartell, eds., Ann Arbor Science, Ann Arbor, Mich., 29-42.

Water Resources Planning Committee. (1986). The relationships between fish community distribution and their ecologic environment in the Tamshui River, Water Resources Planning Committee, Taiwan (in Chinese).

Zimmermann, H. J. (1991). Fuzzy set theory and its applications, Kluwer Academic, Boston. 